\section{Prevención de las infecciones oportunistas en pacientes infectados por el virus de la inmunodeficiencia humana $^{1}$}

Palabras clave. Infecciones oportunistas, virus de la inmunodeficiencia humana, quimioprofilaxis, tratamiento antirretrovírico de gran actividad, TARGA.

\footnotetext{
1 Basado en el documento "2001 USPHS/IDSA guidelines for the prevention of opportunistic infections in persons infected with human immunodeficiency virus", elaborado por el Servicio de Salud Pública (USPHS) y la Sociedad de Enfermedades Infecciosas (IDSA) de los Estados Unidos de América. Disponible en http://www. hivatis.org/guidelines/OIGuidelines (acceso el 12 de agosto de 2001).
}

Desde la descripción de los primeros casos de sida, hace 20 años, en los países industrializados se han hecho importantes adelantos para mejorar la supervivencia y la calidad de vida de los pacientes infectados por el virus de la inmunodeficiencia humana (VIH). El tratamiento antirretrovírico de gran actividad (TARGA), introducido en 1995, es la forma más eficaz de prevenir las infecciones oportunistas y debería ser considerado en todo paciente en el que esté indicado. No obstante, la profilaxis específica frente a las infecciones oportunistas sigue siendo útil en los casos que no responden a este tratamiento o no pueden o no quieren tomarlo, e incluso en pacientes sometidos a TARGA. Como el TARGA puede restaurar la función inmunitaria, la quimioprofilaxis frente a las infecciones oportunistas no tiene por qué ser administrada de por vida. La susceptibilidad a las infecciones oportunistas se puede definir en función del recuento de linfocitos T (LT) CD4+. La suspensión de los regímenes profilácticos primarios y secundarios tiene varias ventajas: simplifica los tratamientos, incrementa la adherencia a los mismos y reduce la toxicidad, las interacciones farmacológicas y los costos.

En 1995, el Servicio de Salud Pública (U.S. Public Health Service: USPHS) y la Sociedad de Enfermedades Infecciosas (Infectious Diseases Society of America: IDSA) de los Estados Unidos de América publicaron unas directrices para la prevención de las infecciones oportunistas en pacientes infectados por VIH que son revisadas periódicamente. Desde la última revisión, de 1999, se han producido algunos cambios importantes, entre los que destacan las siguientes recomendaciones:

- Interrumpir la profilaxis primaria de la neumonía por Pneumocystis carinii y de la infección diseminada por el complejo Mycobacterium avium cuando el TARGA incremente el recuento de LT CD4+ a más de 200 y $100 / \mu \mathrm{L}$, respectivamente, durante al menos tres meses.

- Interrumpir la profilaxis primaria frente a la toxoplasmosis cuando el recuento de LT CD4+ aumente a más de $200 / \mu \mathrm{L}$ durante 3 meses.

- Interrumpir la profilaxis secundaria de la neumonía por $P$. carinii en pacientes con recuentos de LT CD4+ > 200/ $\mu \mathrm{L}$ durante un mínimo de 3 meses. 
- Interrumpir la profilaxis secundaria de la infección diseminada por complejo $M$. avium en pacientes con recuento de LT CD4+ > 100/ $\mu \mathrm{L}$ durante más de 6 meses si han completado 12 meses de tratamiento frente al complejo $M$. avium y no presentan signos ni síntomas de infección diseminada por este microorganismo.

- Interrumpir la profilaxis secundaria frente a la toxoplasmosis y la criptococosis en pacientes con recuento de LT CD4+ > 200/ $\mu \mathrm{L}$ y $>100-200 / \mu \mathrm{L}$, respectivamente, durante más de 6 meses, siempre que hayan completado el tratamiento inicial y no presenten signos ni síntomas atribuibles a estos patógenos.

- Realizar pruebas de detección del virus de la hepatitis $C$ en todos los pacientes infectados por VIH.

Además, la presente revisión proporciona información adicional sobre la transmisión de la infección por herpesvirus humanos de tipo 8 y las interacciones farmacológicas, particularmente entre la rifampicina y los antirretrovíricos, y nuevas recomendaciones sobre la inmunización de los niños y adultos expuestos o infectados por VIH.

Las recomendaciones están clasificadas de acuerdo con una versión revisada del sistema de cinco letras y tres números de la IDSA (cuadro 1), donde las letras representan el tipo de recomendación y los números romanos la calidad de las pruebas en las que se basa.

\section{NEUMONÍA POR PNEUMOCYSTIS CARINII}

\section{Prevención de la exposición}

No hay datos suficientes para recomendar que todos los pacientes infectados por $\mathrm{VIH}$ con riesgo de sufrir neumonía por $P$. carinii (NPC) no sean hospitalizados en la misma habitación que un paciente con NPC (CIII).

\section{Prevención de la enfermedad}

Comienzo de la profilaxis primaria. Los adultos y adolescentes, incluidas las embarazadas y los tratados con TARGA, deben recibir quimioprofilaxis frente a la NPC cuando tengan un recuento de LT CD4+ $<200 / \mu \mathrm{L}$ (AI) o antecedentes de candidiasis orofaríngea (AII). La quimioprofilaxis también se debe considerar en pacientes con porcentajes de linfocitos T CD4+ < 14\% o antecedentes de enfermedades que definen el sida (BII). Cuando no sea posible efectuar recuentos de LT CD4+ al menos cada 3 meses, se puede iniciar la quimioprofilaxis con recuentos $>200$, pero $<250 / \mu \mathrm{L}$ (BII).

El fármaco recomendado es la trimetoprimasulfametoxazol (TMP-SMZ) (AI), que también confiere protección frente a la toxoplasmosis y a algunas infecciones respiratorias bacterianas comunes. Siempre que sea posible, la profilaxis no se debe interrumpir en pacientes con reacciones adversas que no pongan en peligro la vida; cuando se haya interrumpido por este motivo, se debe reinstaurar una vez que la reacción adversa se haya resuelto (AII). La reinstauración del tratamiento puede ser mejor tolerada si se hace con incrementos graduales de la dosis (BI).

En caso de intolerancia a la TMP-SMZ, las alternativas son la dapsona (BI), la dapsona más pirimetamina y ácido folínico (BI), la pentamidina en aerosol administrada con el nebulizador Respirgard IITM (BI) y la atovacuona (BI), igual de eficaz que la pentamidina o la dapsona (BI), pero considerablemente más cara que los demás regímenes. En pacientes seropositivos a Toxoplasma gondii que no toleren la TMP-SMZ, las alternativas recomendadas para la profilaxis simultánea de la NPC y de la toxoplasmosis incluyen la dapsona más pirimetamina (BI) o la atovacuona, con o sin pirimetamina (CIII).

Interrupción y reinicio de la profilaxis primaria. Se recomienda interrumpirla cuando el TARGA au-

CUADRO 1. Tipo de recomendaciones y calidad de las pruebas en las que se basan

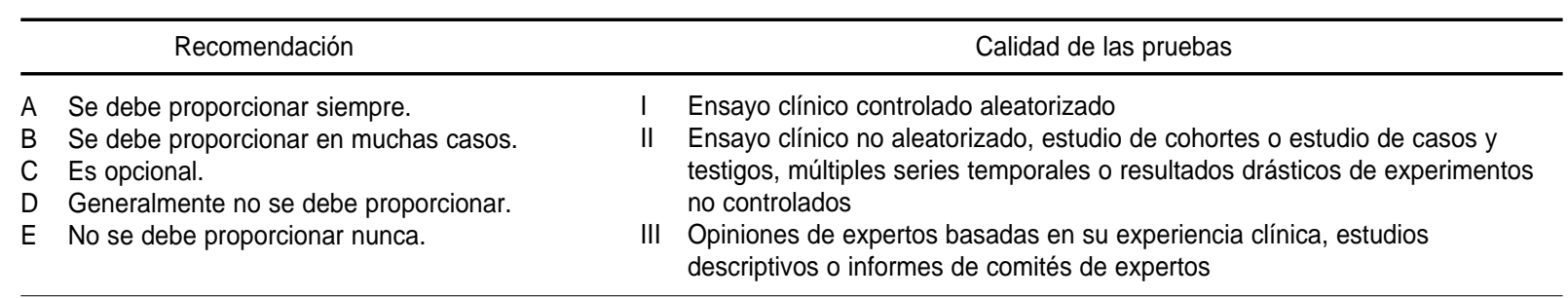


mente los LT CD4+ por encima de $200 / \mu \mathrm{L}$ durante al menos 3 meses (AI) y reiniciarla cuando vuelvan a disminuir a menos de $200 / \mu \mathrm{L}$ (AIII).

Prevención de las recurrencias. Los pacientes con antecedentes de NPC deben recibir profilaxis secundaria (tratamiento de mantenimiento crónico) de por vida (AI), a no ser que el TARGA proporcione una recuperación del sistema inmunitario.

Interrupción y reinicio de la profilaxis secundaria. La profilaxis secundaria se debe interrumpir cuando el TARGA incremente los LT CD4+ de < $200 / \mu \mathrm{L}$ a $>200 / \mu \mathrm{L}$ durante al menos 3 meses (BII); cuando el epidosio de NPC haya ocurrido con cifras $>200 / \mu \mathrm{L}$, la prudencia aconseja seguir con la profilaxis de por vida, independientemente de las cifras que se alcancen con el TARGA (CIII). La profilaxis se reiniciará cuando los LT CD4+ bajen a $<200 / \mu \mathrm{L}$ (AIII) o aparezca un nuevo episodio de NPC, aunque el recuento de LT sea $>200 / \mu \mathrm{L}$ (CIII).

Consideraciones especiales. A los recién nacidos de mujeres infectadas por VIH se les debe administrar profilaxis con TMP-SMZ desde las 4 a 6 semanas de vida hasta el año (AII). El tratamiento se interrumpirá si posteriormente se demuestra que no están infectados. La necesidad de seguir con la profilaxis más allá del año depende del recuento de LT CD4+ según la edad (AII). No se ha determinado la seguridad de interrumpir la profilaxis en niños sometidos a TARGA. Los niños con antecedentes de NPC deben recibir quimioprofilaxis de por vida para evitar las recurrencias (AI).

Las embarazadas deben recibir quimioprofilaxis frente a la NPC como cualquier otro adulto o adolescente (AIII). El fármaco de elección es la TMP-SMZ o, como alternativa, la dapsona. Debido al posible riesgo de efectos teratógenos de la profilaxis se puede aplazar hasta después del primer trimestre. También se puede administrar pentamidina en aerosol, dado que, en ausencia de absorción sistémica, no se produce exposición del embrión (CIII).

\section{ENCEFALITIS POR TOXOPLASMA}

\section{Prevención de la exposición}

Poco después del diagnóstico de la infección por VIH se debe realizar una prueba de anticuerpos
IgG frente a Toxoplasma gondii para identificar infecciones latentes (BIII).

Todas las personas infectadas por VIH, y en particular las que no tienen IgG anti-Toxoplasma, deben ser informadas de las diferentes fuentes de infección por Toxoplasma, y en particular de que no deben comer carne cruda o poco cocinada ni frutas y vegetales crudos sin lavar (BIII), así como de las precauciones que deben tomar si tienen gatos (BIII).

\section{Prevención de la enfermedad}

Comienzo de la profilaxis primaria. A los pacientes seropositivos a Toxoplasma con recuentos de LT CD4 $+<100 / \mu \mathrm{L}$ se les debe administrar profilaxis frente a la encefalitis por Toxoplasma (AII). El fármaco de elección es la TMP-SMZ (AII). En caso de intolerancia, la alternativa recomendada es la dapsona-pirimetamina, que también es eficaz frente a la NPC (BI). También se puede administrar atovacuona, con o sin pirimetamina (CIII). Los datos actuales no permiten recomendar la monoterapia profiláctica con dapsona, pirimetamina, azitromicina o claritromicina (DII). La pentamidina en aerosol no confiere protección frente a la encefalitis por Toxoplasma (EI).

A los pacientes seronegativos a Toxoplasma que no estén tomando un régimen profiláctico frente a la NPC que también sea activo frente a la encefalitis por Toxoplasma se les debe repetir la prueba de anticuerpos IgG anti-Toxoplasma cuando el recuento de LT CD4+ baje de $100 / \mu \mathrm{L}$, para determinar si han sufrido seroconversión y están en riesgo de padecer encefalitis por Toxoplasma (CIII). Si así fuera, se les administrará profilaxis, como se ha descrito anteriormente (AII).

Interrupción y reinicio de la profilaxis primaria. Se puede interrumpirla en pacientes en los que el TARGA aumente los LT CD4+ por encima de $200 / \mu \mathrm{L}$ durante al menos 3 meses (AI) y se debe reiniciarla cuando bajen nuevamente por debajo de 100-200/ $\mu \mathrm{L}$ (AIII).

Prevención de las recurrencias. Los pacientes que hayan completado el tratamiento inicial frente a la encefalitis por Toxoplasma deben recibir profilaxis secundaria de por vida (AI), a no ser que el TARGA produzca una recuperación del sistema inmunitario (CIII). La combinación de pirimetamina, sulfadiazina y ácido folínico es altamente eficaz en esta indicación (AI). En pacientes que no toleran las sulfamidas se utiliza frecuentemente la combinación de 
pirimetamina y clindamicina (BI), que, al contrario de la combinación de pirimetamina y sulfadiazina, no es eficaz también frente a la NPC (AII).

Interrupción y reinicio de la profilaxis secundaria. La interrupción se puede considerar en pacientes que hayan completado con éxito el tratamiento inicial de la encefalitis por Toxoplasma y en los que el TARGA mantenga el recuento de LT CD4+ por encima de $200 / \mu \mathrm{L}$ durante al menos 6 meses (CIII). Algunos expertos son partidarios de realizar una resonancia magnética cerebral antes de tomar esta decisión. La profilaxis secundaria se debe reiniciar cuando los LT CD4+ vuelvan a bajar de $200 / \mu \mathrm{L}$ (AIII).

Consideraciones especiales. La profilaxis de la NPC con TMP-SMZ también previene la toxoplasmosis. Lo mismo debería ocurrir con la atovacuona (CIII). Los niños de más de 1 año en los que esté indicada la profilaxis de la NPC y estén recibiendo un fármaco distinto de la TMP-SMZ o la atovacuona deberían ser sometidos a pruebas serológicas de Toxoplasma (BIII). Aquellos con inmunosupresión grave que no estén recibiendo TMP-SMZ o atovacuona y sean seropositivos para Toxoplasma deben recibir un régimen profiláctico eficaz frente a la NPC y a la toxoplasmosis, como dapsona más pirimetamina (BIII).

A las embarazadas se les puede administrar un régimen profiláctico frente a la encefalitis por Toxoplasma similar al descrito para la NPC (AIII). Debido al riesgo de efectos teratógenos, los regímenes que contienen pirimetamina se pueden aplazar hasta después del embarazo (CIII). Los casos de transmisión vertical de Toxoplasma son raros cuando la infección materna ha ocurrido hace tiempo. En lactantes hijos de mujeres infectadas por VIH y Toxoplasma se debe investigar la presencia de toxoplasmosis congénita (BIII).

\section{CRIPTOSPORIDIOSIS}

\section{Prevención de la exposición}

Los pacientes infectados por VIH deben recibir información acerca de las múltiples formas de transmisión de Cryptosporidium (BIII), entre las que se encuentran el contacto directo con pacientes infectados, el consumo de agua o alimentos contaminados y el simple contacto con agua contaminada durante actividades recreativas. Los pacientes deben evitar el contacto con heces humanas y animales, lavarse las manos después de cambiar pañales o de tener contacto con animales de compañía o con la tierra, evitar los contactos sexuales oroanales
(BIII) y evitar la exposición a animales como los terneros y los corderos y a las instalaciones donde se crían (BII). Tampoco deben beber directamente agua de lagos y ríos (AIII) y deberían evitar bañarse en agua probablemente contaminada, aunque sea agua salada (BIII).

Ha habido varios brotes de criptosporidiosis que se han relacionado con el suministro municipal de agua. Durante estos brotes es aconsejable hervir el agua 1 minuto (AI), utilizar filtros o consumir agua embotellada (CIII). Cuando sea recomendable hervir el agua, esto se aplicará igualmente a la preparación de las leches artificiales para lactantes (AII). El hielo hecho con agua contaminada también puede ser fuente de infección. Otra posible fuente de infección son las ostras (BIII). Los individuos infectados por Cryptosporidium no deberían manipular alimentos (BII). En los hospitales, las precauciones habituales deberían ser suficientes para evitar la transmisión de un paciente infectado a un paciente susceptible infectado por VIH (BII). No obstante, algunos expertos recomiendan que estos pacientes no compartan habitación con pacientes con criptosporidiosis (CIII).

\section{Prevención de la enfermedad}

No hay agentes quimioprofilácticos de eficacia demostrada frente a la criptosporidiosis ni fármacos de eficacia demostrada para evitar las recurrencias.

\section{MICROSPORIDIOSIS}

\section{Prevención de la exposición}

Exceptuando el lavado de las manos y otras medidas de higiene personal, no hay forma de reducir el riesgo de exposición.

\section{Prevención de la enfermedad}

No hay regímenes quimioprofilácticos eficaces para prevenir la microsporidiosis ni regímenes quimioterapéuticos eficaces para prevenir su recurrencia.

\section{TUBERCULOSIS}

\section{Prevención de la exposición}

Los pacientes infectados por VIH deben ser informados de las actividades y ocupaciones que pueden aumentar la probabilidad de que se vean 
expuestos a la tuberculosis (TBC) (BIII), como el trabajo en instituciones sanitarias o penitenciarias, $\mathrm{O}$ en asilos para personas sin hogar.

\section{Prevención de la enfermedad}

Cuando se identifique la infección por vez primera se debe realizar una prueba de Mantoux. Si es positiva se debe obtener una radiografía de tórax y realizar un examen clínico para descartar la TBC activa. En pacientes infectados por VIH con síntomas compatibles con TBC se deben tomar rápidamente estas medidas, independientemente de los resultados de la prueba de la tuberculina (AII). Si la prueba es positiva, deben ser tratados frente a la TBC latente, aunque no haya pruebas de TBC activa ni antecedentes de tratamiento de TBC activa o latente. Las opciones incluyen la isoniazida administrada diariamente (AII) o dos veces a la semana (BI) durante 9 meses, o 2 meses de tratamiento con rifampicina y pirazinamida (AI), o rifabutina y pirazinamida (BIII). Como los pacientes infectados por VIH corren el riesgo de presentar neuropatía periférica, los tratados con isoniazida deben recibir piridoxina (BIII). La observación directa está indicada en caso de tratamiento intermitente (AI) y siempre que ello sea posible desde el punto de vista operativo (BIII).

Los pacientes infectados por VIH en contacto estrecho con pacientes con TBC infecciosa deben ser tratados frente a la TBC latente, independientemente de la edad, de los resultados de la prueba de la tuberculina y de tratamientos anteriores, una vez que se haya descartado la existencia de TBC activa (AII). En pacientes expuestos a TBC resistente a la isoniazida o a la rifampicina, la decisión de utilizar regímenes quimioprofilácticos distintos de la monoterapia con isoniazida, de la rifampicina más pirazinamida o de la rifabutina más pirazinamida se debe basar en el riesgo relativo de exposición a microorganismos resistentes y después de consultar a las autoridades de salud pública (AII).

Aunque la fiabilidad de la prueba de la tuberculina disminuye a medida que disminuye el recuento de LT CD4+, debería considerarse su repetición anual cuando sea inicialmente negativa, en pacientes con un considerable riesgo de exposición a Mycobacterium tuberculosis (BIII) y en pacientes inicialmente negativos cuya función inmunitaria haya mejorado (recuento de LT CD4+ > 200/ $\mu \mathrm{L}$ ) con el TARGA (BIII). La vacunación con bacilo de Calmette-Guérin (BCG) está contraindicada por el riesgo de enfermedad diseminada (EII).

Prevención de las recurrencias. El tratamiento supresor crónico no es necesario en pacientes que hayan completado con éxito un régimen terapéutico antituberculoso recomendado (DII).

Consideraciones especiales. La rifampicina puede inducir el metabolismo de todos los inhibidores de las proteasas e inhibidores de la transcriptasa inversa no nucleosídicos y reducir sus concentraciones a niveles subterapéuticos. No se debe administrar rifampicina con amprenavir, indinavir, lopinavir/ritonavir, nelfinavir, saquinavir o delavirdina, pero sí se puede administrar con ritonavir más saquinavir, efavirenz $\mathrm{y}$, posiblemente, con nevirapina. La rifabutina es una alternativa aceptable de la rifampicina, pero no se debe administrar con gel duro de saquinavir o con delavirdina y se recomienda precaución con el gel blando de saquinavir, porque los datos existentes son escasos. Con muchos de estos antirretrovíricos es necesario hacer ajustes de la dosis de rifabutina.

A los hijos de mujeres infectadas por VIH se les debe realizar una prueba de la tuberculina entre los 9 y los 12 meses de edad y repetirla al menos una vez al año (AIII). En niños infectados por VIH que convivan con individuos con prueba de tuberculina positiva se debe investigar la posible existencia de TBC (AIII), y a los expuestos a pacientes con TBC activa se les debe administrar tratamiento profiláctico después de descartar la existencia de TBC activa, independientemente de los resultados de la prueba de la tuberculina (AII).

A las mujeres infectadas por VIH con tuberculina positiva o antecedentes de exposición a un caso de TBC activa se les debe administrar quimioprofilaxis antituberculosa después de descartar la TBC activa (AIII). Antes de iniciar el tratamiento se debe obtener una radiografía de tórax con adecuada protección abdominopélvica. Cuando no haya antecedentes de exposición a $M$. tuberculosis resistente, el tratamiento de elección es la isoniazida diaria o dos veces a la semana. Debido al riesgo de efectos teratógenos, el inicio del tratamiento se puede aplazar hasta después del primer trimestre. La experiencia con la rifampicina y rifabutina es menor, pero no parecen asociarse a desenlaces adversos de la gestación. La pirazinamida de debe evitar, sobre todo en el primer trimestre.

\section{INFECCIÓN DISEMINADA POR EL COMPLEJO MYCOBACTERIUM AVIUM}

\section{Prevención de la exposición}

Los microorganismos del complejo M. avium (CMA) son frecuentes en la comida y el agua, pero 
no hay recomendaciones específicas para evitar la exposición.

\section{Prevención de la enfermedad}

Comienzo de la profilaxis primaria. Los adultos y adolescentes infectados por VIH deben recibir quimioprofilaxis frente a la infección diseminada por CMA cuando el recuento de LT CD4+ sea $<50 / \mu \mathrm{L}$ (AI). Los fármacos de elección son la claritromicina o la azitromicina (AI). Como alternativa se puede utilizar la rifabutina, aunque las interacciones farmacológicas dificultan su uso (BI). No se debe usar la combinación de claritromicina y rifabutina, porque no es más eficaz, pero sí puede ocasionar más efectos adversos (EI). La combinación de azitromicina y rifabutina sí es más eficaz que la azitromicina por sí sola, pero el mayor costo, la mayor frecuencia de efectos adversos y las posibles interacciones farmacológicas no permiten recomendarla de forma generalizada (CI). La claritromicina y la azitromicina también proporcionan protección frente a las infecciones respiratorias bacterianas (BII). Antes de iniciar la profilaxis hay que descartar la existencia de enfermedad diseminada y para ello puede ser necesario hacer hemocultivos. Además, también se debe descartar la TBC activa antes de iniciar la profilaxis con rifabutina. No hay datos suficientes para recomendar de forma generalizada la obtención de muestras respiratorias y gastrointestinales para detectar la presencia de CMA (DIII).

Interrupción y reinicio de la profilaxis primaria. La profilaxis primaria se debe interrumpir cuando el TARGA incremente los LT CD4+ a más de $100 / \mu \mathrm{L}$ durante al menos 3 meses (AI), y se debe reiniciar cuando bajen a menos de $50-100 / \mu \mathrm{L}$ (AIII).

Prevención de las recurrencias. Los pacientes con infección diseminada por CMA deben recibir profilaxis secundaria de por vida (AII), a no ser que el TARGA restablezca su función inmunitaria. Siempre que no haya pruebas sólidas de resistencia a los macrólidos, se debe utilizar claritromicina o azitromicina, combinadas con etambutol (AII), con o sin rifabutina (CI). Debido a una mayor mortalidad, la claritromicina no se debe administrar a dosis de $1000 \mathrm{mg}$ dos veces al día (EI), sino de $500 \mathrm{mg}$ dos veces al día. No se debe utilizar la clofazimina (DII).

Interrupción y reinicio de la profilaxis secundaria. La interrupción se puede considerar en pacientes que hayan completado un tratamiento frente al CMA de al menos un año, que sigan asintomáticos con respecto al CMA y en los que el TARGA haya incrementado el recuento de LT CD4+ a más de $100 / \mu \mathrm{L}$ durante al menos 6 meses (CIII). Antes de ello, algunos expertos recomiendan obtener hemocultivos para confirmar la inactividad de la enfermedad. La profilaxis se reiniciará cuando el recuento de LT CD4+ vuelva a ser $<100 / \mu \mathrm{L}$ (AIII).

Consideraciones especiales. La rifabutina no se debe administrar en pacientes tratados con algunos inhibidores de la proteasa e inhibidores no nucleosídicos de la transcriptasa inversa por sus complejas y todavía mal conocidas interacciones farmacológicas. La claritromicina también puede tener interacciones farmacológicas con estos antirretrovíricos, aunque no hay datos para recomendar ajustes de las dosis. En cambio, la farmacocinética de la azitromicina no se ve afectada por el sistema de la citocromoxidasa $\mathrm{P} 450$, por lo que no hay riesgo de interacciones farmacológicas con estas dos clases de antirretrivíricos

A los niños se les debe administrar profilaxis frente a la infección diseminada por CMA cuando los recuentos de LT CD4+ sean $<50 / \mu \mathrm{L}$ en los de 6 a 12 años, $<75 / \mu L$ en los de 2 a 6 años, $<500 / \mu L$ en los de 1 a 2 años, y $<750 / \mu \mathrm{L}$ en los menores de 1 año (AII). Al igual que en los adultos, los fármacos preferidos son la claritromicina y la azitromicina (AII), de los que existen suspensiones orales. La posibilidad de interrumpir la profilaxis en caso de que el TARGA aumente los linfocitos $\mathrm{T}$ no ha sido investigada en niños.

En las embarazadas, la quimioprofilaxis debe seguir las mismas normas que en los demás adultos y adolescentes (AIII). Debido al riego de efectos teratógenos, el inicio de la profilaxis se puede aplazar hasta el segundo trimestre. El fármaco de elección parece ser la azitromicina (BIII). La experiencia con la rifabutina en el embarazo es escasa, y la claritromicina se debe evitar por sus efectos teratógenos. El régimen preferido para la profilaxis secundaria consiste en azitromicina más etambutol (BIII).

\section{INFECCIONES RESPIRATORIAS BACTERIANAS}

\section{Prevención de la exposición}

Como Streptococcus pneumoniae y Haemophilus influenzae son frecuentes en el medio extrahospitalario, no hay formas eficaces de reducir la exposición a estas bacterias. 


\section{Prevención de la enfermedad}

A los adultos y adolescentes con recuentos de LT CD4+ $\geq 200 / \mu \mathrm{L}$ se les debe administrar una dosis de la vacuna neumocócica 23-valente si no la han recibido en los 5 años anteriores (BII). También se puede considerar la vacunación en pacientes con recuentos de LT CD4+ <200/ $\mu \mathrm{L}$, aunque no hay pruebas clínicas de su eficacia en estos casos (CIII). La revacunación es recomendable en pacientes vacunados inicialmente cuando el recuento de LT CD4+ era $<200 / \mu \mathrm{L}$, pero en los que este haya aumentado a $>200 / \mu \mathrm{L}$ con el TARGA (CIII). Se desconoce la duración de la eficacia protectora de la vacuna. La revacunación cada 5 años también podría ser válida para los individuos infectados por VIH, igual que para los no infectados (CIII), pero no hay pruebas de que proporcione beneficios clínicos. Generalmente no se recomienda la vacunación contra $H$. influenzae tipo B en adultos, dada su baja incidencia en este grupo (DIII).

La profilaxis de la NPC con TMP-SMZ también reduce la frecuencia de infecciones respiratorias bacterianas, hecho a tener en cuenta en la selección del fármaco a utilizar en la profilaxis de la NPC (AII). Sin embargo, el uso indiscriminado de este fármaco incrementaría la incidencia de resistencia, motivo por el cual no se debe administrar únicamente con el fin de prevenir las infecciones respiratorias bacterianas. Lo mismo se puede decir de la claritromicina (DIII).

Como la neutropenia asociada con la infección por VIH o con los tratamientos farmacológicos incrementa el riesgo de infecciones bacterianas, incluida la neumonía, es conveniente controlar esta alteración mediante la interrupción del tratamiento con fármacos mielosupresores (CII) o la administración de factor estimulador de las colonias de granulocitos (CII).

Prevención de las recurrencias. A los pacientes infectados por VIH con infecciones respiratorias bacterianas recurrentes muy frecuentes se les puede administrar quimioprofilaxis (CIII). Entre los antibióticos que se pueden utilizar con este fin se encuentran la TMP-SMZ y la claritromicina o azitromicina.

Consideraciones especiales. A los menores de 5 años infectados por VIH se les debe adminisrar la vacuna frente a $H$. influenzae tipo b (AII) y la vacuna conjugada antineumocócica (BII). Los mayores de 2 años también deben recibir la vacuna antineumocócica 23-valente (BII), que se volverá a administrar 3 a 5 años más tarde en los niños antes de los 10 años, y 5 años más tarde en los mayores de 10 años (BIII). Para evitar infecciones bacterianas graves en niños hipogammaglobulinémicos se deben utilizar inmunoglobulinas intravenosas (IGIV) (AI), que también pueden ser útiles en niños con infecciones bacterianas graves y recurrentes (BI), pero pueden no proporcionar beneficios adicionales en los que ya estén siendo tratados diariamente con TMP-SMZ. Para evitar la recurrencia de infecciones respiratorias bacterianas graves también se puede administrar quimioprofilaxis (BI), aunque hay que ser cauto debido al riesgo de aparición de microorganismos resistentes y toxicidad de los fármacos.

En embarazadas infectadas por VIH se recomienda la vacunación antineumocócica, siempre que no hayan sido vacunadas en los 5 años anteriores (BIII). Como la vacunación se ha asociado en adultos no gestantes a un aumento transitorio de la replicación del $\mathrm{VIH}$, puede aplazarse hasta que se haya iniciado el TARGA, con el fin de evitar la transmisión perinatal del VIH (CIII).

\section{INFECCIONES ENTÉRICAS BACTERIANAS}

\section{Prevención de la exposición}

Alimentos. Los pacientes infectados por VIH no deben comer diversos alimentos crudos o poco cocinados (huevos, carnes, pescados y mariscos) $\mathrm{ni}$ productos lácteos y jugos de frutas no pasteurizados, y deben ser informados de cómo evitar la contaminación cruzada de los alimentos (BIII). La listeriosis es una enfermedad grave cuya incidencia, generalmente baja, está muy aumentada en pacientes con inmunodepresión grave causada por el VIH, quienes pueden adoptar varias medidas relacionadas con la alimentación para reducir el riesgo de adquirir esta infección.

Animales de compañía. Los pacientes deben evitar adquirir animales de compañía de menos de 6 meses, especialmente si tienen diarrea (BIII), y evitar también el contacto con cualquier animal con diarrea (BIII), así como el contacto con reptiles, debido al riesgo de salmonelosis (BIII).

Viajes. Los viajes a países en desarrollo incrementan el riesgo de infecciones alimentarias o transmitidas por el agua, y los pacientes deben evitar los alimentos y bebidas posiblemente contaminados (AII).

\section{Prevención de la enfermedad}

A los viajeros generalmente no se les recomienda la quimioprofilaxis (DIII), pero es una 
medida que debe considerarse en pacientes infectados por $\mathrm{VIH}$, dependiendo de su grado de inmunosupresión, del destino y de la duración del viaje (CIII). Entre los fármacos de primera elección se encuentran las fluoroquinolonas (CIII) y, como alternativa, la TMP-SMZ (BIII).

Prevención de las recurrencias. Los pacientes infectados por VIH con septicemia por Salmonella necesitan profilaxis secundaria a largo plazo para evitar las recurrencias. Los fármacos de elección suelen ser las fluoroquinolonas, en particular el ciprofloxacino, siempre que los microorganismos sean susceptibles a ellas (BII). Es necesario determinar si los contactos domésticos de estos pacientes con salmonelosis o shigelosis son portadores asintomáticos, con el fin de adoptar medidas higiénicas estrictas o instaurar un tratamiento con antibióticos para evitar la transmisión recurrente (CIII).

Consideraciones especiales. En los niños, el lavado de las manos tras el contacto con animales de compañía debe ser supervisado por adultos (BIII). A los niños con inmunodepresión grave se les debe administrar tratamiento frente a la gastroenteritis salmonelósica con el fin de evitar su diseminación extraintestinal (CIII); los casos que hayan sufrido septicemia necesitan tratamiento a largo plazo para prevenir la recurrencia (CIII); el fármaco de elección es la TMP-SMZ. En los niños no se recomiendan los fármacos antiperistálticos (DIII).

Dado que el embarazo incrementa el riesgo de listeriosis, las embarazadas infectadas por VIH deben recibir información sobre la forma de evitar esta infección (BII). Como la diseminación extraintestinal de la Salmonella durante el embarazo puede producir infección amnioplacentaria que conduzca a la pérdida del feto, la gastroenteritis por Salmonella requiere tratamiento en las embarazadas (BIII). Durante el embarazo no se deben administrar fluoroquinolonas.

\section{BARTONELOSIS}

\section{Prevención de la exposición}

Los pacientes inmunodeprimidos corren un alto riesgo de sufrir bartonelosis grave, que puede ser transmitida por los gatos, y deben conocer los riesgos de poseer gatos (CIII). Cuando adquieran uno, debe ser mayor de 1 año y estar sano (BII). Hay que evitar los arañazos (BII) y cualquier herida producida por un gato debe ser lavada inmediatamente (CIII).

\section{Prevención de la enfermedad}

No hay datos que demuestren la eficacia de la quimioprofilaxis de las enfermedades por Bartonella (CIII).

Prevención de las recurrencias. Se puede considerar la profilaxis a largo plazo con eritromicina o doxiciclina (CIII).

Consideraciones especiales. Cuando en la casa haya un niño infectado por VIH, los padres deben ser informados de los riesgos de poseer gatos (CIII). En caso de que sea necesaria la profilaxis a largo plazo durante el embarazo, se debe utilizar eritromicina. La tetraciclina está contraindicada en el embarazo.

\section{CANDIDIASIS}

\section{Prevención de la exposición}

La presencia de Candida en la piel y mucosas es frecuente y no hay medidas para reducir la exposición a estos hongos.

\section{Prevención de la enfermedad}

Aunque el fluconazol puede reducir el riesgo de candidiasis mucosa y criptococosis, no se recomienda la profilaxis primaria generalizada debido a la eficacia del tratamiento de la enfermedad aguda, a la baja mortalidad de la candidiasis mucosa, al riesgo de aparición de resistencia e interacciones farmacológicas y al costo de la profilaxis (DIII).

Prevención de las recurrencias. Por estos mismos motivos, muchos expertos tampoco recomiendan la profilaxis crónica de la candidiasis orofaríngea o vulvovaginal recurrente. No obstante, si las recurrencias son frecuentes o graves, se puede administrar fluconazol (CI) o itraconazol (CI) por vía oral. Los adultos y adolescentes con múltiples episodios de candidiasis esofágica son candidatos al tratamiento supresor crónico con antifúngicos como el fluconazol (BI).

Consideraciones especiales. En niños no está indicada la profilaxis primaria (DIII). En niños con candidiasis mucocutánea recurrente grave se puede administrar profilaxis secundaria con azoles sisté- 
micos (CIII), sobre todo en caso de candidiasis esofágica (BIII).

La experiencia con los antifúngicos sistémicos durante el embarazo es escasa, pero los pocos datos existentes contraindican su uso (DIII) y en caso de embarazo se debe suspender su administración (DIII). En mujeres tratadas con azoles se deben instaurar medidas anticonceptivas eficaces (AIII).

\section{CRIPTOCOCOSIS}

\section{Prevención de la exposición}

Las personas infectadas por VIH no pueden evitar totalmente la exposición a Cryptococcus neoformans. No hay pruebas de que la exposición a las heces de paloma se asocie con un aumento del riesgo de adquirir criptococosis.

\section{Prevención de la enfermedad}

No se recomienda la realización habitual de pruebas de detección de antígenos criptocócicos debido a la poca probabilidad de que los resultados influyan sobre las decisiones clínicas (DIII). El fluconazol y el itraconazol pueden reducir la frecuencia de la criptococosis en pacientes con enfermedad avanzada por VIH, pero la mayoría de los expertos no recomiendan la profilaxis rutinaria debido a la frecuencia relativamente baja de la enfermedad, a la ausencia de beneficios en términos de supervivencia, a las posibles interacciones farmacológicas, a la posible aparición de resistencia a los antifúngi$\cos$ y al costo. No obstante, se puede administrar fluconazol en pacientes con recuentos de LT CD4+ $<50 / \mu \mathrm{L}(\mathrm{CI})$.

Prevención de las recurrencias. A los pacientes que hayan completado el tratamiento inicial de la criptococosis se les debe administrar profilaxis secundaria de por vida (AI), a no ser que el TARGA conduzca a la recuperación del sistema inmunitario. El fármaco preferido es el fluconazol, superior al itraconazol (AI).

Interrupción y reinicio de la profilaxis secundaria. La profilaxis secundaria se puede suspender cuando el paciente haya completado con éxito el tratamiento inicial de la criptococosis, siga estando asintomático con respecto a la criptococosis y el TARGA produzca un aumento de los LT CD4+ a más de 100 a 200/ $\mu \mathrm{L}$ durante más de 6 meses (CIII).
Antes de tomar esta medida, algunos expertos prefieren realizar cultivos de líquido cefalorraquídeo. El tratamiento de mantenimiento debe recomenzar cuando los LT CD4+ vuelvan a bajar a menos de 100 a $200 / \mu \mathrm{L}$ (AIII).

Consideraciones especiales. En niños, tras un primer episodio de criptococosis, es recomendable la profilaxis secundaria de por vida (AII).

En el embarazo no se debe administrar profilaxis con fluconazol o itraconazol, debido, entre otros motivos, a sus posibles efectos teratógenos (DIII). Si la mujer queda embarazada durante la profilaxis primaria, se debe interrumpir el tratamiento. En caso de que sea necesario seguir con la profilaxis secundaria durante la gestación, es preferible la anfotericina B, sobre todo durante el primer trimestre. Las mujeres tratadas con derivados azólicos necesitan medidas anticonceptivas eficaces (AIII).

\section{HISTOPLASMOSIS}

\section{Prevención de la exposición}

Aunque no es posible evitar completamente la exposición a Histoplasma capsulatum en áreas endémicas, los pacientes con recuentos de LT CD4+ $<200 / \mu L$ deben evitar actividades asociadas con un aumento del riesgo, como levantar polvo del suelo, limpiar gallineros, limpiar, remodelar o demoler edificios antiguos y explorar cuevas (CIII).

\section{Prevención de la enfermedad}

Ni las pruebas cutáneas con histoplasmina ni las pruebas serológicas de anticuerpos o antígenos permiten predecir la enfermedad en zonas endémicas, por lo que no se recomienda su realización (DII). El itraconazol puede reducir la frecuencia de histoplasmosis en pacientes con infección avanzada por VIH residentes en zonas endémicas de $H$. capsulatum, pero no se han observado beneficios relacionados con la supervivencia. La profilaxis con este antifúngico se puede considerar en pacientes con recuentos de LT CD4+ $<100 / \mu \mathrm{L}$ y alto riesgo condicionado por la exposición ocupacional o la residencia en zonas hiperendémicas (CI).

Prevención de las recurrencias. Después de completar el tratamiento inicial de la histoplasmosis se torna necesaria la profilaxis secundaria de por vida con itraconazol (AI). 
Interrupción de la profilaxis secundaria. Aunque el riesgo de recurrencia puede ser bajo en pacientes en los que el recuento de LT CD4+ aumente a más de $100 / \mu \mathrm{L}$ con el TARGA, no hay datos suficientes para hacer recomendaciones con respecto a la interrupción de la profilaxis.

Consideraciones especiales. Como en los niños se pueden producir infecciones diseminadas, tras un episodio de enfermedad es razonable administrar profilaxis secundaria de por vida (AIII).

Debido a la embriotoxicidad y teratogenia del itraconazol en modelos animales, no se debe administrar profilaxis primaria durante la gestación (DIII). Para la profilaxis secundaria es preferible la anfotericina B, sobre todo durante el primer trimestre. Las mujeres tratadas con derivados azólicos necesitan medidas anticonceptivas eficaces (AIII).

\section{COCCIDIOIDOMICOSIS}

\section{Prevención de la exposición}

Aunque no es posible evitar completamente la exposición a Coccidioides immitis en zonas endémicas, dentro de lo posible se deben evitar las actividades asociadas con un aumento del riesgo, como las excavaciones o la exposición a tormentas de polvo (CIII).

\section{Prevención de la enfermedad}

Las pruebas cutáneas con coccidioidina (esferulina) no permiten predecir la enfermedad en zonas endémicas, por lo que no se recomienda su realización (DII); la positividad de la prueba serológica puede indicar un aumento del riesgo de infección activa, pero tampoco se debe realizar de forma rutinaria (DIII). Para las personas que viven en zonas endémicas, habitualmente no se recomienda la profilaxis primaria.

Prevención de las recurrencias. Los pacientes que hayan completado el tratamiento inicial de la coccidioidomicosis deben recibir profilaxis secundaria de por vida (AII) con fluconazol o itraconazol oral. La meningitis requiere consultar a un experto.

Interrupción de la profilaxis secundaria. Aunque el riesgo de recurrencia sistémica puede ser bajo en pacientes en los que el recuento de LT CD4+ au- mente a más de $100 / \mu \mathrm{L}$ con el TARGA, no hay datos suficientes para hacer recomendaciones con respecto a la interrupción de la profilaxis.

Consideraciones especiales. Aunque no hay datos específicos sobre la coccidioidomicosis en niños infectados por VIH, es razonable administrar profilaxis secundaria de por vida tras un episodio agudo (AIII).

Para la profilaxis secundaria en embarazadas se prefiere la anfotericina $B$, especialmente en el primer trimestre. Las mujeres tratadas con derivados azólicos necesitan medidas anticonceptivas eficaces (AIII).

\section{ENFERMEDADES POR CITOMEGALOVIRUS}

\section{Prevención de la exposición}

Cuando no haya datos para suponer que el paciente sea seropositivo para citomegalovirus, se le debe realizar una prueba de anticuerpos (BIII). Entre estos pacientes se encuentran los que no sean consumidores de drogas por vía parenteral y los varones que no hayan tenido relaciones homosexuales. Para reducir el riesgo de exposición al CMV y a otros patógenos de transmisión sexual se deben utilizar siempre preservativos durante las relaciones sexuales (AII). Tanto los niños que acuden a guarderías (BIII) como sus padres corren mayor riesgo de adquirir infecciones por CMV (BI). El riesgo de infección puede disminuir con buenas prácticas higiénicas, como el lavado de las manos (AII). Siempre que no se trate de situaciones urgentes, los pacientes expuestos al VIH o infectados por este virus que sean seronegativos para CMV solo deben recibir productos sanguíneos negativos para anticuerpos anti-CMV (BIII).

\section{Prevención de la enfermedad}

En adolescentes y adultos infectados por VIH que sean seropositivos para CMV y tengan recuentos de LT CD4+ <50/ $\mu \mathrm{L}$ se puede administrar profilaxis con ganciclovir oral (CI). El aciclovir no es eficaz para la prevención de las enfermedades por CMV y el valaciclovir no es recomendable por su tendencia a aumentar la mortalidad de los pacientes con sida que lo están recibiendo como profilaxis anti-CMV. Por lo tanto, ninguno de los dos es recomendable con este fin (EI). El mejor método para prevenir la enfermedad grave por CMV consiste en la identificación rápida de las manifestaciones de la enfermedad. Algunos expertos recomiendan la rea- 
lización periódica de fundoscopias en pacientes con recuentos de $\mathrm{LT} \mathrm{CD} 4+<50 / \mu \mathrm{L}(\mathrm{CIII})$.

Prevención de las recurrencias. La enfermedad por CMV no se cura con la administración temporaria de los antivíricos disponibles en la actualidad. Por consiguiente, tras el tratamiento de inducción se recomienda la profilaxis secundaria de por vida (AI), a no ser que el TARGA produzca la recuperación del sistema inmunitario. Los regímenes de eficacia demostrada incluyen el ganciclovir por vía parenteral $\mathrm{u}$ oral, el foscarnet por vía parenteral, la combinación de ganciclovir y foscarnet por vía parenteral, el cidofovir por vía parenteral y, en la retinitis, los implantes intraoculares de ganciclovir o las inyecciones intravítreas repetidas de fomivirsen (AI). El tratamiento intraocular no proporciona protección al ojo contralateral ni a otros órganos y se suele combinar con ganciclovir oral.

Interrupción y reinicio de la profilaxis secundaria. En casos de retinitis, la interrupción es recomendable en pacientes en los que el TARGA incremente el recuento de LT CD4+ a más de 100 a 150/ $\mu \mathrm{L}$ durante más de 6 meses (BII). La decisión se debe tomar tras consultar a un oftalmólogo, teniendo en cuenta la magnitud y duración del aumento de los LT CD4+, la localización anatómica de la lesión retiniana, la visión del ojo contralateral y la posibilidad de realizar controles oftalmológicos periódicos (BII). Estos controles deben proseguir aunque se interrumpa la profilaxis secundaria (AIII). La profilaxis se reiniciará cuando el recuento de LT CD4+ vuelva a ser $<50 / \mu \mathrm{L}$. (AIII).

Consideraciones especiales. Algunos expertos recomiendan obtener urocultivos de CMV en todos los recién nacidos infectados por $\mathrm{CMV}$, con el fin de identificar la infección congénita (CIII). En los niños seronegativos con inmunodepresión grave, a partir del año de vida se pueden realizar pruebas de anticuerpos anuales (CIII) con el fin de identificar a los que hayan adquirido la infección y puedan beneficiarse de las pruebas de detección de retinitis. Los niños con inmunodepresión grave e infección por CMV pueden beneficiarse de la realización de una fundoscopia cada 4 a 6 meses (CIII). En niños con inmunodepresión grave se puede administrar profilaxis primaria con ganciclovir oral (CII). No hay datos suficientes para hacer recomendaciones sobre la interrupción de la profilaxis secundaria en niños.

En embarazadas, las indicaciones de la profilaxis son las mismas que en pacientes no gestantes.

\section{ENFERMEDADES POR VIRUS DEL HERPES SIMPLE}

\section{Prevención de la exposición}

Los pacientes infectados por VIH deben utilizar siempre preservativos durante las relaciones sexuales con el fin de evitar la exposición al virus del herpes simple (VHS) y a otros patógenos de transmisión sexual (AII). Además, deberían evitar los contactos sexuales con personas que tengan lesiones herpéticas evidentes, tanto genitales como bucolabiales (AII).

\section{Prevención de la enfermedad}

La profilaxis antivírica no es necesaria tras la exposición al VHS ni para evitar los episodios iniciales en pacientes con infección latente (DIII).

Prevención de las recurrencias. Como los episodios de enfermedad por VHS se pueden tratar con éxito, tras la resolución de las lesiones no es necesario el tratamiento crónico con aciclovir. Sin embargo, cuando las recurrencias son frecuentes o graves se puede administrar profilaxis secundaria con aciclovir oral o famciclovir tópico (AI). Otra opción es el valaciclovir (CIII). Cuando los virus son resistentes al aciclovir y, generalmente, también al ganciclovir, se puede recurrir al foscarnet o al cidofovir por vía intravenosa (AII).

Consideraciones especiales. Las recomendaciones sobre la prevención de los episodios iniciales y de las recurrencias en adolescentes y adultos son aplicables también a los niños.

La profilaxis oral con aciclovir hacia el final del embarazo es una estrategia controvertida recomendada por algunos expertos con el fin de evitar la transmisión neonatal del herpes. Sin embargo, no se recomienda la adopción de esta medida de forma rutinaria. En pacientes con recurrencias frecuentes y graves de herpes genital puede estar indicada la profilaxis con aciclovir (BIII).

\section{ENFERMEDADES POR VIRUS VARICELA-ZÓSTER}

\section{Prevención de la exposición}

Los niños y adultos infectados por VIH que sean susceptibles al virus varicela-zóster (VVZ), esto es, aquellos que no tengan antecedentes de varicela 
ni zóster o que sean seronegativos para el VVZ, deben evitar la exposición a pacientes con varicela o zóster (AII). Los contactos domésticos de pacientes susceptibles, especialmente los niños, deben ser vacunados frente al VVZ si no tienen antecedentes de varicela ni están infectados por el VIH, con el fin de evitar que transmitan el virus a sus contactos susceptibles infectados por el VIH (BIII).

\section{Prevención de la enfermedad}

Hay muy pocos datos sobre la eficacia y seguridad de la vacuna contra la varicela en adultos infectados por VIH, por lo que no se pueden hacer recomendaciones al respecto. Para evitar la varicela, a los niños y adultos susceptibles al VVZ se les debe administrar inmunoglobulina antivaricela-zóster tan pronto como sea posible (siempre antes de 96 horas) tras el contacto con un paciente que tenga varicela o zóster (AIII). No hay datos sobre la eficacia del aciclovir en la prevención de la varicela en niños y adultos susceptibles y no existen medidas profilácticas frente al zóster.

Prevención de las recurrencias. No hay fármacos de eficacia demostrada para prevenir la recurrencia del zóster en pacientes infectados por VIH.

Consideraciones especiales. Los niños infectados por VIH que se encuentren asintomáticos y no estén inmunodeprimidos deben recibir la vacuna atenuada a los 12 a 15 meses de edad, o más tarde (BII). En el resto de los casos no se debe administrar la vacuna por el riesgo de infección diseminada (EIII).

En embarazadas susceptibles al VVZ se recomienda la administración de inmunoglobulina antivaricela-zóster en las 96 horas siguientes a la exposición (AIII). Si se está utilizando aciclovir oral, se debe realizar una prueba serológica para interrumpir la administración del fármaco en caso de que la paciente sea seropositiva para VVZ (BIII).

\section{INFECCIÓN POR HERPESVIRUS HUMANO DE TIPO 8 (VIRUS DEL HERPES ASOCIADO AL SARCOMA DE KAPOSI)}

\section{Prevención de la exposición}

Las personas infectadas por VIH y HHV-8 corren el riesgo de padecer sarcoma de Kaposi. Los pacientes deben ser informados de las tres vías principales de transmisión del HHV-8 (saliva, semen y sangre) y de sus implicaciones (CIII). Aunque no se ha establecido la eficacia de los preservativos en la prevención de la exposición al HHV-8, los pacientes deben utilizar siempre preservativos durante las relaciones sexuales para reducir la exposición a los patógenos de transmisión sexual (AII). Aunque ya estén infectados por VIH, los adictos a drogas intravenosas no deben compartir el material de inyección para evitar la infección por HHV-8 y otros patógenos (BIII).

\section{Prevención de la enfermedad}

No hay recomendaciones específicas sobre la necesidad de pruebas serológicas ni sobre el uso de fármacos potencialmente útiles desde el punto de vista profiláctico, como el ganciclovir, el foscarnet o el cidofovir. Las combinaciones de antirretrovíricos potentes que suprimen la replicación del VIH reducen la frecuencia del sarcoma de Kaposi y deberían administrarse en todos los casos en los que estén indicadas (BII).

Prevención de las recurrencias. La supresión eficaz de la replicación del VIH con antirretrovíricos debería evitar la progresión del sarcoma de Kaposi o la aparición de nuevas lesiones y debería tenerse en cuenta en todo paciente con sarcoma de Kaposi (BII).

Consideraciones especiales. En regiones donde el HHV-8 es endémico se han descrito casos de transmisión maternoinfantil y de transmisión entre niños pequeños, probablemente a través de la saliva. No obstante, todavía no hay recomendaciones para evitar la transmisión del virus entre niños.

\section{INFECCIÓN POR PAPILOMAVIRUS HUMANOS}

\section{Prevención de la exposición}

Aunque hay pocas pruebas de que los preservativos disminuyan el riesgo de infección por papilomavirus humanos (PVH), los pacientes infectados por VIH deben utilizar siempre preservativos durante las relaciones sexuales para reducir la exposición a los patógenos de transmisión sexual (AII). 


\section{Prevención de la enfermedad}

Cánceres epiteliales genitales asociados con PVH en mujeres infectadas por VIH. Tras el diagnóstico de la infección por VIH se debe realizar un frotis de Papanicolaou cada 6 meses durante el primer año $\mathrm{y}$, si los resultados son normales, repetirlo anualmente a partir de entonces (AII). En pacientes con células escamosas atípicas de significado indeterminado (ASCUS) hay varias opciones. En general, si no hay sospecha de neoplasia, se puede repetir el frotis cada 4 a 6 meses durante 2 años o hasta que se obtengan tres frotis con resultados negativos. Si durante estos dos años se vuelve a obtener un diagnóstico de ASCUS, se puede considerar la posibilidad de efectuar una colposcopia (BIII). En caso de sospecha de neoplasia se debe proceder como si la paciente tuviera una lesión intraepitelial escamosa de bajo grado (LSIL) (BIII).

En pacientes con LSIL también hay varias opciones, como la colposcopia con biopsia dirigida (BIII) o la repetición del frotis cada 4 a 6 meses y la realización de una colposcopia con biopsia dirigida en caso de que se obtengan resultados persistentemente anormales (BIII). Ante un diagnóstico de lesión intraepitelial escamosa de alto grado o carcinoma de células escamosas se debe practicar una colposcopia con biopsia dirigida (AII). No hay datos para recomendar modificaciones de estas pautas en mujeres sometidas a TARGA.

Neoplasias intraepiteliales y cánceres anales asociados con PVH en mujeres y en varones homosexuales infectados por VIH. Todavía son necesarios nuevos estudios antes de que se pueda recomendar la realización rutinaria de exámenes citológicos anales en estos casos.

Prevención de las recurrencias. El riesgo de recurrencia de las lesiones intraepiteliales escamosas y del cáncer cervical está en aumento en las mujeres infectadas por VIH, por lo que se deben realizar exámenes citológicos frecuentes, seguidos de colposcopia cuando esté indicada (AI). Es posible que el 5-fluorouracilo intravaginal a bajas dosis reduzca el riesgo de recurrencia a corto plazo, pero todavía no hay datos suficientes para recomendar su uso rutinario.

Consideraciones especiales. Durante el embarazo no se recomienda el uso de 5-fluorouracilo intravaginal para evitar la recurrencia de las lesiones.

\section{INFECCIÓN POR EL VIRUS DE LA HEPATITIS C}

\section{Prevención de la exposición}

En los Estados Unidos de América, la principal vía de transmisión del virus de la hepatitis $C$ (VHC) es el consumo de drogas intravenosas. A los pacientes se les debe aconsejar que abandonen esta práctica (AIII) y que entren en un programa de tratamiento de la toxicomanía (AIII). Si siguen consumiendo drogas por esta vía, hay que recomendarles que no reutilicen ni compartan el instrumental de inyección (BIII). Asimismo, se les debe advertir de los riesgos del tatuaje (BIII), de que el consumo intranasal de drogas ilegales también se asocia con la transmisión del VHC y de que no deben compartir el instrumental de aspiración (BIII). Tampoco se deben compartir cuchillas de afeitar y otros artículos de higiene personal (BIII). Aunque la eficiencia de la transmisión sexual del VHC es baja, se recomienda el uso de preservativos para reducir el riesgo de exposición a patógenos de transmisión sexual (AII).

\section{Prevención de la enfermedad}

Se deben realizar pruebas de detección del VHC en todas las personas infectadas por VIH (BIII). Con este fin, se deben utilizar inmunoensayos enzimáticos aprobados para la detección de anticuerpos anti-VHC en sangre (BIII). Los resultados positivos deben ser confirmados mediante RIBA $^{\mathrm{TM}}$ o reacción en cadena de la polimerasa con transcriptasa inversa. En pacientes con sospecha de infección por VHC o con signos de hepatopatía también se debe proceder a la detección del ARN del virus mediante la reacción en cadena de la polimerasa con transcriptasa inversa, aunque los anticuerpos sean negativos (CIII).

Los pacientes infectados por VIH y VHC deben moderar el consumo de alcohol (AII) y, de ser posible, evitarlo totalmente (CIII). Los pacientes con hepatitis $\mathrm{C}$ crónica deben ser vacunados frente a la hepatitis $\mathrm{A}$ debido al riesgo de hepatitis A fulminante (BIII). Si son susceptibles, también deben ser vacunados frente a la hepatitis B (BIII). La coinfección por VIH y VHC requiere controles frecuentes de las enzimas hepáticas, pero no la interrupción del TARGA (DIII).

Prevención de las recurrencias. Todavía no se conoce la duración de la respuesta al tratamiento de la hepatitis $\mathrm{C}$ ni la necesidad de tratamiento de mantenimiento en pacientes coinfectados por VIH y VHC. 
Consideraciones especiales. La transmisión vertical del VHC parece ser más frecuente en mujeres coinfectadas por VIH y VHC que en las infectadas únicamente por VHC. Por consiguiente, los recién nacidos de estas mujeres deben ser sometidos a pruebas de detección de la infección por VHC (BI), pero solo después de los 2 años de edad, puesto que los anticuerpos anti-VHC maternos pueden persistir hasta los 18 meses. Para un diagnóstico más temprano se puede recurrir a la reacción en cadena de la polimerasa con transcriptasa inversa, realizada al mes de vida y repetida posteriormente. Los datos sobre la evolución natural de la infección por VHC y el tratamiento de la hepatitis $C$ crónica son escasos en niños. El tratamiento antivírico de la hepatitis $C$ no está aprobado para menores de 18 años.

SYNOPSIS

Preventing opportunistic infections in persons infected with human immunodeficiency virus

Highly active antiretroviral therapy (HAART), which has been provided since 1995 to patients infected with human immunodeficiency virus (HIV), has produced noticeable results in regard to preventing opportunistic infections in this population. Nevertheless, it is still useful to administer specific prophylactic treatment against opportunistic infections in patients treated with HAART and also in patients who do not respond to HAART or who cannot or do not wish to take that treatment. Prophylactic treatment can be halted when, due to HAART, there is a sustained increase in the CD4+ T-lymphocytes count (that count indicates the degree of susceptibility that a person has to opportunistic infections).

Guidelines for preventing opportunistic infections were developed in 1995 by the United States Public Health Service and the Infectious Diseases Society of America, and they have been reviewed periodically. The last review, done in 1999, marked the introduction of important changes regarding clinical parameters to halt primary and secondary prophylaxis against Pneumocystis carinii pneumonia, Toxoplasma gondii, and Mycobacterium avium complex. These changes, along with the latest information concerning the transmission of human herpesviruses, immunization of children infected with HIV or exposed to the virus, and certain drug interactions, are the major focus of this review.

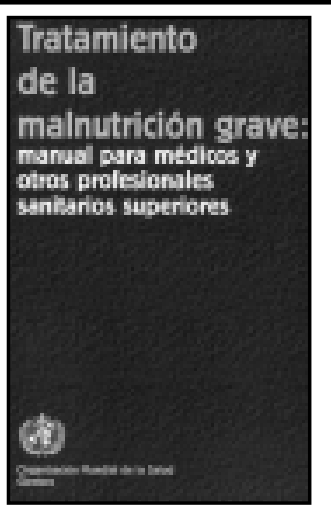

1999, 62 pp.,

ISBN 9243545116

Código: WHO 22,

Precios: US\$14.00/

US\$10.00 en América

Latina y el Caribe

\section{Tratamiento de la malnutrición grave: manual para médicos y otros profesionales sanitarios superiores}

Este manual proporciona directrices prácticas para el tratamiento de pacientes con malnutrición grave. Su finalidad es promover el mejor tratamiento existente para reducir el riesgo de defunción, acortar la estancia hospitalaria y facilitar la rehabilitación y la recuperación completas. Se hace hincapié en le tratamiento de los niños gravemente malnutridos en hospitales y centros de salud; también se aborda brevemente el tratamiento de los niños muy malnutridos en situaciones de desastre en los campamentos de refugiados, así como de los adolescentes y adultos con malnutrición grave.

El manual está destinado principalmente al personal que trabaja en instituciones sanitarias centrales y de distrito, como médicos, enfermeras, nutricionistas, dietistas y personal auxiliar, así como a organizaciones de ayuda que trabajan en campamentos de refugiados.

http://publications.paho.org • Fax: (301) 206-9789•Correo electrónico:paho@pmds.com 